\title{
In Memoriam Professor Bernhard Mühlschlegel
}

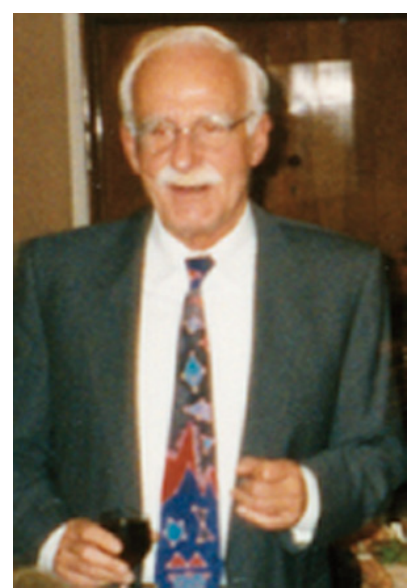

Bernhard Mühlschlegel was born in Berlin 13.9.1925, he grew up in Berlin, got his Ph.D. 1953 at the A.v. Humboldt University, was Prof. at the Univ. of Köln since 1962, he died 18.7.2007 in Köln and is buried in Berlin. I suppose he would be very happy to know that we do not forget him.

We met "Onkel Bernhard" as intimate friends called him, including my wife, already 1960 at the University of Illinois, where we both learnt physics from the great master J. Bardeen. Already then as in later years Bernhard Mühlschlegel was at the centre of an international community of interesting people, well informed about good work and often in a gentleman like way critical to us and at the same time helpful. As my wife frequently expressed during discussions "He is a special person", elegant his taste and we agreed.

As important facts of his biography indicate his life is characterizable by important invariants: Berlin was to a large extent his "home" , as was "cluster- and mesoscopic physics", see first publication B. Mühlschlegel: Zur Messung der Lichtabsorption an mikroskopischen Pulvern [Ann. Physik (Leipzig) 9, 29 (1951)], his open mind and taste for elegance and significance, see papers from B. Mühlschlegel with D. Scalapino on electronic heat capacity and susceptibility of small particles [Phys. Rev. Lett. 26, 707 (1971)]; thermodynamic properties of small superconducting particles [Phys. Rev. B 6, 1767 (1972)], and more recently on Hubbard clusters together with G. Pastor; for many years he referred to the work of Kubo and Friedel, for example, as goals of quality for the mesoscopic scientific community, he was faithful to his friends all over the world, exchanging views and ideas, in particular to the "Berliners" which he supported during difficult (political) times and which he visited regularly when he was "home" again. Sitting together, drinking coffee and chatting, all in an elegant style, he liked. During critical discussions he was usually well balanced and frequently helped in his unique humorous way those with over bursting "temperament" to integrate peacefully and to find the correct argument.

During his times at the University of Köln he strongly influenced the rebuilding of modern Solid State Physics in Germany (see special issue of Ann. der Physik 14, 9-10 (2005) dedicated to B. Mühlschlegel) and also for several years as the Editor of the Annalen der Physik. B. Mühlschlegel strongly improved again the scientific quality of this historically important Journal.

Last time I saw "Onkel Bernhard" shortly before he died I asked him: Bernhard, what shall we do without you? He smiled!

K. Bennemann

(Berlin, Oct. 2008) 